\section{Canadian History and Media}

By J.c. Mahé

In July 1982 four agencies collaborated to offer a new course in the Departmen
of Secondary Education at the University Ed CI 497 Canadian History and Media received a very positive reactio from its participants. The purpose of the answers for the course's success. Moreover the article encourages different educational agencies to re-think and requestion the lechnological orientation atbe replaced in a theoretical mode beyond the practical and the strategical.
Will education accept the challenge of looking at film in an innovative way? cinemas that recently number of new ton (31 in 1981-82 alone), one must conclude that film increasingly reaches more and more people. This proliferation tional system at some time or other. However, it is noteworthy that film re mains, despite its popularity, isolated
from curriculum and pedagogical thinking in education. Consequently, it is comncompass mini-courses, conferences, workshops and units on film with a stricttion. All these efforts seem to happen devoid of integrated and theoretical foundation, of questioning the nature of film as experience and as medium.
In July 1982 twenty secondary teachers participated in a Canadian History and Media credit course offered at the

University of Alberta.
Ed CI 497 was co-sponsored by agen-
cies such as the National Film cies such as the National Fil CBC and the Department of Secondary
Education of the University of Alberta. Classes were officed in an immersion 22:00 every day for a period of two weeks. The syllabus contained amon others the following presentation:

The History of the Documentary

Thought
Get the Chicken not the Facts: Film in the Classroom

Research, Development and Produc tion or The Champions Research Techniques

Jean-Claude Mahé, B. Ed, is a distribuBoard in Edmonton, and has had over 10 years experience in the field of teaching
The Development of Critical View ing Skills

t Media on Political and Written course evaluations indicated hat Ed CI 497 was a resoundingly succes full experience: participants were eager to recommend his innovative course sion. Why was such an experience in the trenches of Kiva Room at the University of Alberta evaluated so positively? The purpose of the present article is to more, the aim is to uproot greater possibilities for the re-happening of film in education.

nnovation vs Evolution

Institutions in general want to be part of state, evolution, innovation. a high The four agencies that collaborated in offering Ed CI 497 this summer wer plek' thereby assuming an innovative role. To begin with, it is necessary in education to distinguish between two concepts, innovation and evolution
Evolution implies Eomething new] buties innovatio slow and continuing process, desirous of change. It is often informal and conscious-less. Innovation on the con-
trary is conscious, voluntary, thought-full [réfléchi\}. It is a call for change based on a firm foundation: a revolutionary enterprise.
Innovation by its very nature requires time, thinking, research and a willingness to change something. The above definition also allows us to distinguish between true innovations and those that merely
arise from a desire to ameliorate the efficacy of a system or its idealized counterpart of practicality. Evolution therefore
has it that education adapts film within this practical and efficacious model.
If educational institutions funiversities or example) were to redefine education objectives relating to the innovative
teaching of film, the question would become: Is it possible for a University to stuctures of its system? The above question would lead us to lengthy discussion on different types of innovations. Suffice it to establish that for to look beyond course content, method pedagogical limits or educational environment. We have to redefine all of these, however, and we must also look at which inmitment to change the system ferent ways of thinking and reflecting on has it that education adapts film with
this practical and efficacious model.
Innovation, then primarily implies an disciplines where art and philosophy bring a fresh orientation beyond the practical and the strategical. The structure must explode and re-formulate pedagogy
to the what-ness of film. Ed CI 497 gave to the what-ness of "ilm. Ed Cef an "avant-gout" of this explosion. As one teacher expressed it recently, "I have a feeling we were served something
unusual and extra-ordinary in your

Theory vs Practice

In an era of E.T. and PAC-MAN ( word directed at a specific ideology), where The classical dichotomy in education finally becomes: theory versus practic or departments have different ideas, so different that they can't or won't make the effort to understand the differences
each of them possesses. each of them possesses.
Education in general has not questioned (remettre en question) the technology of film or media. It has blindly asked for more hardware, rationalizing that the and teachers would encounter, the greater the learning that would result.

Universities and audio-visual agencies
have followed suit in manufacturing audio-visual specils in and consultans watest Sony machine to assigned teachers Feeling guilty for not disposing of more than a few minutes to explain the
wonders of the new anti-glare screen they then call for workshops. These have to be practical, for teachers shouldn't think, be knowledgeable or resourceful. Specialists in technology are also statistics equals inform out statistics, for equals knowledge. In some ways powering ideology. It has virtually stop
pols the 'image'.

To counterpoise the above mould of technology which annihilates thinking. reflecting, and creation, we will have Macdonald in his article How Literal is Curriculum Theory (1982) views theory and practice in a larger framework.
Theory and practice become one. He calls this integration an act of creation. It's ing theory' which encompasses our faculties of imagination, intuition,
analysis and creation. analysis and creation.
The question is now launched, "How can we begin to look at film in an innovative way?" Vainemen

VOLUME 12, NUMBER 4, :983

\section{Board of Directors 1983-84}

Past President

Mr. Tom Rich

Department of Education

Department of Education
C.O. Box 200
Charlottetown, P.E.I. C1A 7N8

President

Dr. Barry Brown
Head, Department of Educational

Communications
College of Education

Saskatoon, Saskatchewan S7N owo

President-Elect

Supervisor of Instructional Materials

Calgary Board of Education

3610 - 9th Street S.E.
Calgary, Alberta T2G 3C5

Secretary/Treasurer

Secretary/Treas
Mr. Ron Eyre

Educational Media Consultant

Wellington County Board of Education

North Guelph, Ontario N1E 6K2

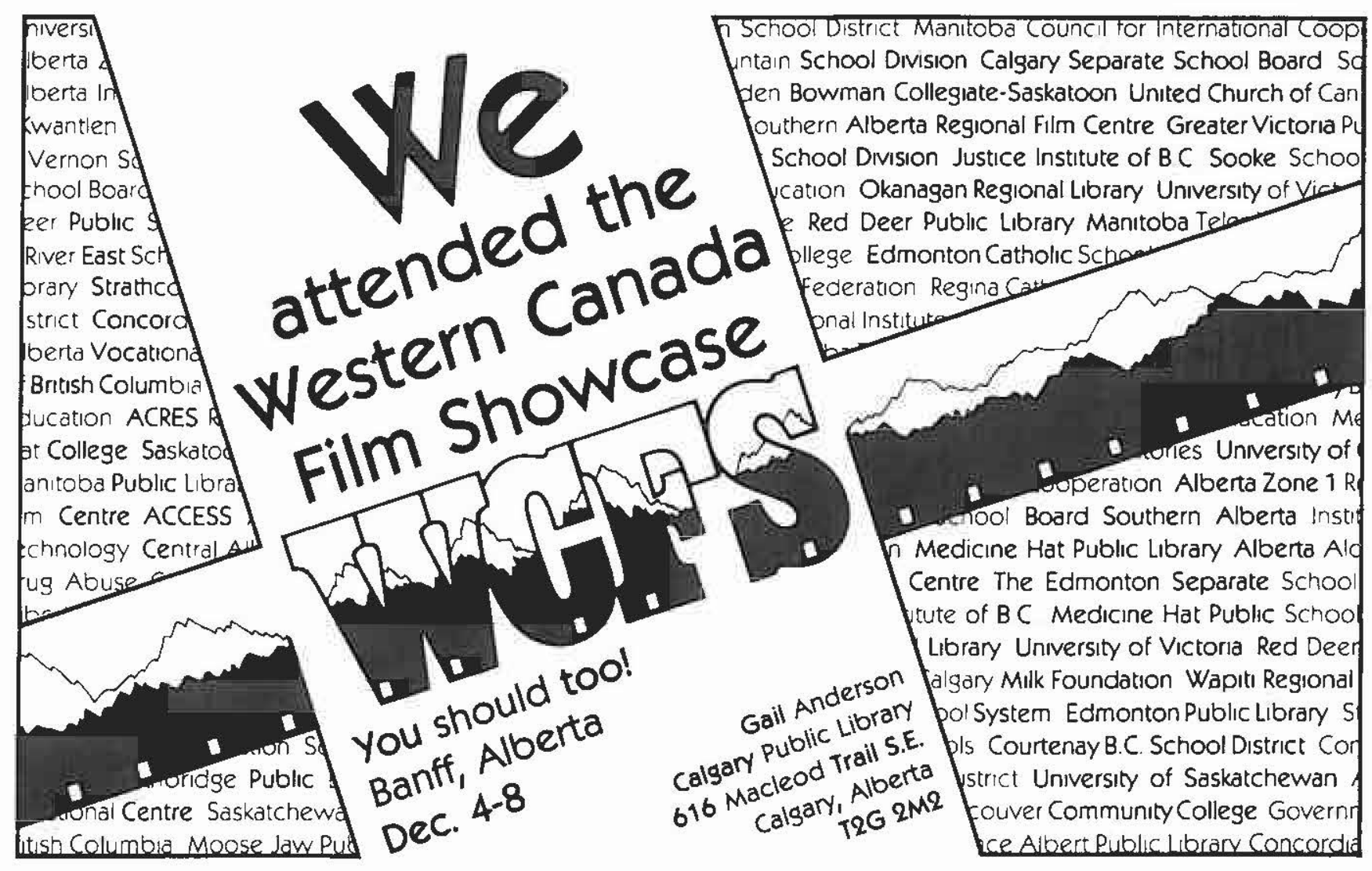

